\title{
The Value of Flexibility in Power Markets
}

\section{Stéphane GOUTTE * and Philippe VASSILOPOULOS ${ }^{\dagger}$}

\section{October 11, 2018}

\begin{abstract}
The concept of flexibility is not one you find in standard microeconomics textbooks, yet it already plays a major role in the remuneration of the resources that generate and consume electricity every day and is likely to play an even larger role with the penetration of large intermittent renewable capacities. In this paper we attempt to quantify the net revenues that can be captured by a flexible resource able to react to the short term price variations on the day-ahead and intraday markets in Germany. We find that the difference between day-ahead and intraday revenues for a flexible resource has been increasing (although the profitability has been decreasing on both markets). This difference is more pronounced once $15 \mathrm{mn}$ price variations can be captured by a flexible resource. The net revenues from the local 15mn auction (which is held 3 hours after the hourly "coupled" day-ahead auction) are more than eight times higher than the day-ahead hourly auction but

*Université Paris 8 (LED), 2 rue de la Liberté, 93526 Saint-Denis Cedex, France. stephane.goutte@univ-paris8.fr

$\dagger^{\dagger}$ EPEX Spot SE, Product Design, 5 Boulevard Montmartre, 75002 Paris, p.vassilopoulos@epexspot.com
\end{abstract}


below the net revenues that can be captured with the high prices from the continuous market. The results of the backward-looking empirical estimations allow us to distinguish and quantify two components of flexibility: (1) the "immediacy" value as we are approaching real-time and the urgency of the delivery increases (this value is revealed during the continuous intraday process and is highly linked to the stochastic nature of power supply and demand (i.e. wind/solar forecasts, forced outages of thermal generation,...) forecast error risk), and (2) the "ramping capability" component based on the technical characteristics as a resource can react to variations of shorter granularity (15mn Vs $60 \mathrm{mn})$. We model and quantify the ramping capability component using a geometric brownian motion with jumps.

Keywords: Intra day; Flexibility; Ramping Capability; Auction; Spot; Volatility; Market Design.

JEL classification: C02, C57, D44, D47, G32, C50.

The findings of this paper were initially presented on the 08 July 2015 at the Conference on "Elements of a new Target Model for European Electricity markets" at the University Paris-Dauphine. This paper has benefited from the support of the Chaire European Electricity Markets of the Paris Dauphine Foundation, supported by RTE, EDF, EPEX Spot and the Groupe Caisse des Dépôts. The views and opinions expressed in this Working Paper are those of the authors and do not necessarily reflect those of the partners of the CEEM. 


\section{Introduction}

As the share of intermittent resources is increasing in the power systems, balancing needs are exacerbated by large and variable generation ramps and forecast deviations of wind and solar adding to the traditional uncertainty of forced plant outages or demand. This is particularly true in the German electricity market where the installed capacity has reached unprecedented levels with more than 90GW of installed wind and solar in 2015. Short term power prices should give the right signals to operate the existing resources and balance the power system (see Schweppe et al. [14]). The framework remains the same, although with a much larger uncertainty injected in the system on the supply side while the ability of consumers to react to price variations has not increased. Discrepancies between a variable supply and a very inelastic demand can lead to higher price volatility and price spikes on the short-term market ${ }^{1}$. Volatility of short term prices could provide additional revenue to the flexible resources able to react (i.e. on a $15 \mathrm{mn}$ time step) and quickly (as real-time approaches).

In this paper we estimate the empirical ("backward-looking") and future ("forwardlooking") net revenues that can be captured by a flexible resource, in our case a CCGT gas turbine, able to react to the short term price variations on the day-ahead and intraday markets in Germany and France. We find that the difference between day-ahead and intraday revenues for a flexible resource has been increasing (although the profitability has been decreasing on both markets).

This difference is more significantly higher once $15 \mathrm{mn}$ price variations can be captured

\footnotetext{
${ }^{1}$ As explained by Garnier and Madlener [6], sales made based on forecasts almost always require the seller to balance. Weber, C., (2010) [17. analyzes the relationship between the physical short-term balancing needs and the traded volumes on the intraday market.
} 
by a flexible resource. Moreover, when we look at the net revenues that stem from the $15 \mathrm{mn}$ auction that takes place every day ahead of delivery at 3pm (for all 96 quarters of tomorrow's delivery) we find that there is a significant "ramping capability" premium compared to the hourly day-ahead auction (that takes place three hours earlier). These "backward-looking" empirical results allow us to quantify two different components for the value of flexibility:

1. The "immediacy" value as we are approaching real-time and the urgency of the delivery increases. This value is revealed during the continuous intraday process and is highly linked to the forecast error risk.

2. The "ramping capability" as a resource can capture variations of shorter granularity. This is more related to the technical characteristics of the asset and its optimization and can be priced already at the day-ahead stage through auctions for $15 / 30 \mathrm{mn}$ products and potentially $5 \mathrm{mn}$ at a later stage.

In the second part of this paper, we analyze this "flexibility" component. We model the different short-term prices (hourly and quarterly auction prices) as mean-reverting jump diffusion (MRJD) process to understand the dynamics of flexibility revenues when the volatility and the number of jumps increase. The model parameters are estimated based on hourly and quarterly price time series. Results of the Monte Carlo simulations show that these revenues start low (1.18 (DE Hourly)- 2.14 (DE Quarter) EUR/MWh) but increase rapidly between 2 and 5 year maturities (7.80 - 14.45 EUR/MWh). At 5 year maturities, auction revenues are seven times higher then their current levels. The revenues from the quarterly market are significantly higher than the hourly revenues. 
These results highlight the importance of the intraday trading and the need to have sub-hourly granularity in the market to reveal the value of flexibility. Over time, although the value of immediacy is likely to decrease with improved forecasting techniques the need to have enough flexibility to account for the large generation ramps will not.

\section{The flexibility challenge}

Variability and uncertainty have always been common characteristics of power systems and managed by grid operators reluctantly with reserves. Because of the limited ability to store electricity, the low demand-side elasticity and the permanent need to match demand and supply, wholesale electricity prices can see extreme price volatility with positive and negative price spikes that can reach thousands of EUR/MWh in both directions (see Nicolosi, M. 2010 [12] for an analysis of negative prices occurrences on the german market). Electricity is traded in Europe usually up to four years ahead of time either bilaterally or exchange based and until the real-time.

The German electricity market can be characterized as a self-scheduling market (as opposed to a central dispatch). Most short-term transactions (hourly and block product: $\left.2^{2}\right)$ are hosted at a day-ahead auction every day ahead of delivery at noon. Continuous bilateral and exchange based trading is pursued until gate closure, typically 30 minutes before real time. In 2014 an auction for 15mn contracts was launched (every day-ahead

\footnotetext{
${ }^{2}$ Block orders are used to link several hours on an all-or-none basis, which means that either the bid is matched on all hours or it is entirely rejected. Block orders allow modelling the behavior of the power plant in the auction.
} 
of delivery at $3 \mathrm{pm}$ for all 96 quarter $\$^{3}$ to complement continuous intraday trading

In 2015, an auction for quarters has been implemented to allow market participants to handle the optimization of their asset/customer portfolio already from the day-ahead (i.e. solar generation ramps that can be anticipated). In Central Western Europe (CWE) subsequently continuous bilateral and exchange based trading of hourly and $15 \mathrm{mn}$ products is pursued until gate closure, typically $30 \mathrm{mn}$ before real-tim 5 .

Traditionally the intraday market has been used to allow market operators to manage their different resources sources of supply and their balance volume risk as a result of:

1. Forced outages of generation units. A power producer that has committed to selling the output of a power plant might need to buy the energy in the intraday if one of its plants becomes unavailable owing to a forced outage.

2. Forecast error of demand. A temperature decrease or cloudiness increase might require additional generation resources to meet load in real-time. The IDM can allow a supplier to purchase this missing energy.

With growing intermittent capacity additions the intraday market is increasingly needed to balance the volume risk associated with the high generation ramps and the forecast errors of intermittent generation. As explained by Garnier and Madlener [6],

\footnotetext{
${ }^{3}$ The opening auction of the intraday market is similar to the auction at 12am. For each $15 \mathrm{mn}$ interval a single (uniform) clearing price is calculated and applied to all transactions for this interval.

${ }^{4}$ most power markets in Europe still have hourly imbalance settlement step and therefore hourly market granularity. Markets with sub-hourly granularity arae for example France and GB with 30mn contracts and Germany, Austria and Benelux with 15mn granularity

${ }^{5}$ The EU power market is based on self-dispatch as opposed to central dispatch in the US. Market participants are encouraged/incentivized to self-balance unforeseen deviations from their day-ahead schedules.

${ }^{6}$ In Germany, in 2015 there were more than $75 \mathrm{GW}$ of installed solar PV or wind capacity.
} 
sales made based on forecasts almost always require the seller to balance. In the absence of resources available within their own portfolios, market participants can turn to the intraday market to avoid imbalance penalties. Forecast errors remain significant (i.e. 5\%) between the day-ahead gate closure and the real-time operations (see Vassilopoulos, P and Salah, A (2013) [16] for an analysis of intraday price and volume dynamics). As demand remains largely price inelastic, within-day variations in generation - even if accurately forecasted - need to be compensated by (1) changing the output from other plants (2) varying interconnection flows, or (3) curtailment of intermittent generation in the most extreme cases.

Intermittent renewable generation (iRES) imposes significant trading needs on market players seeking to balance their portfolios as real-time approaches? Weber, C., (2010) [17. analyzes the relationship between the physical short-term balancing needs and the traded volumes on the intraday market. WIth a surge in wind and solar installed capacity, the forecasts error can account for a large amount of energy. In 2015, more than $37.5 \mathrm{TWh} 8$ were traded on the German intraday market. The following figure shows the evolution of trading volumes between 2009 and 2015 .

\footnotetext{
${ }^{7}$ The move to bring increasing iRES capacity additions closer to wholesale power markets and away from feed-in tariffs impose on iRES generators the balancing risks associated with the intermittency of their generation (See Mauritzen, M. (2015) 11]).

8 https://www.epexspot.com/en/press-media/press/details/press/EPEX_SPOT_reaches_in_ 2015_the_highest_spot_power_exchange_volume_ever
} 
Figure 1: Evolution of Intraday trading volumes in Germany between 2009 and 2015 (source: EPEX SPOT).

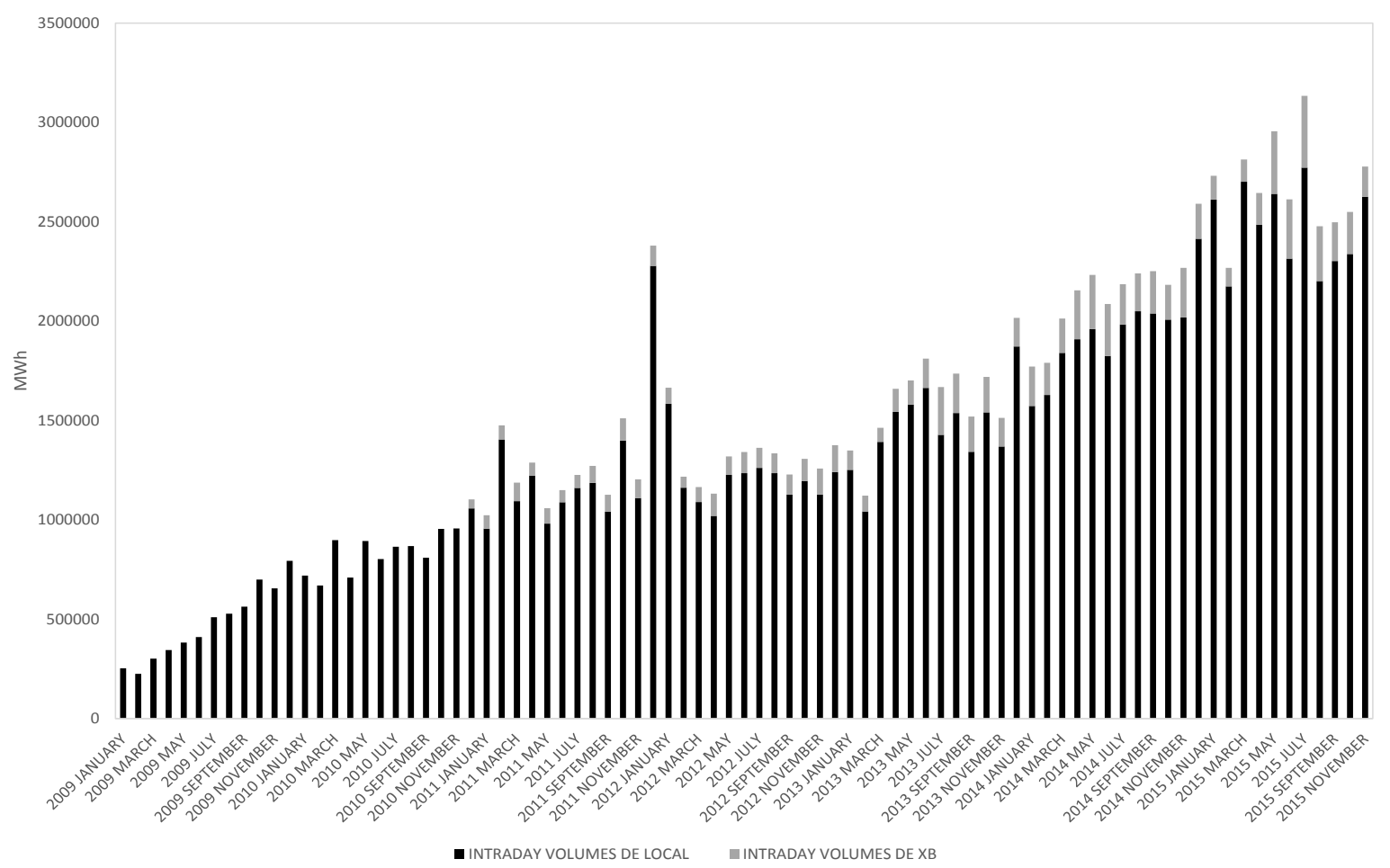

The intermittent nature of solar/wind generation means that if there is not enough flexible capacity to ramp up and down as the intermittent solar and wind output varies, there can be supply discontinuities and price spikes (both negative and positive prices) can appear 9 , On the intraday market, price limits are set at [-9,999EUR/MWh,+ 9,999EUR/MWh] while on the day-ahead market prices cant exceed [-500EUR/MWh, 3,000EUR/MWh].

\footnotetext{
${ }^{9}$ For example, such discontinuities were observed during the solar eclipse on the 20th of March 2015 that created a significant drop in the solar output during the eclipse followed by a sudden increase back to its normal level as the eclipse arrived to an end. Instead of the usual morning/evening ramps, two additional ramps of solar generation appeared and had to be compensated by an increase in thermal generation quickly followed by a decrease in thermal generation. During the first ramp due to the solar eclipse the price of the given quarter jumped to 400EUR/MWh. During the second ramp the price reached -200EUR/MWh. The reader can find more information on this event: "European Power Exchange as a Component of Security of Supply during the Solar Eclipse" [4]
} 
Since 2007 the intraday prices for individual transactions have varied from a maximum of 5,100EUR/MWh to negative 1,499EUR/MWh for individual hours. Figure 2 below shows the evolution of hourly wholesale prices on the Day-ahead and Intraday market (High/Low) in Germany from 01/2013 to 06/2015.

Figure 2: Evolution of hourly wholesale prices on the Day-ahead and Intraday market in Germany from 01/2013 to 06/2015 (source: EPEX SPOT).

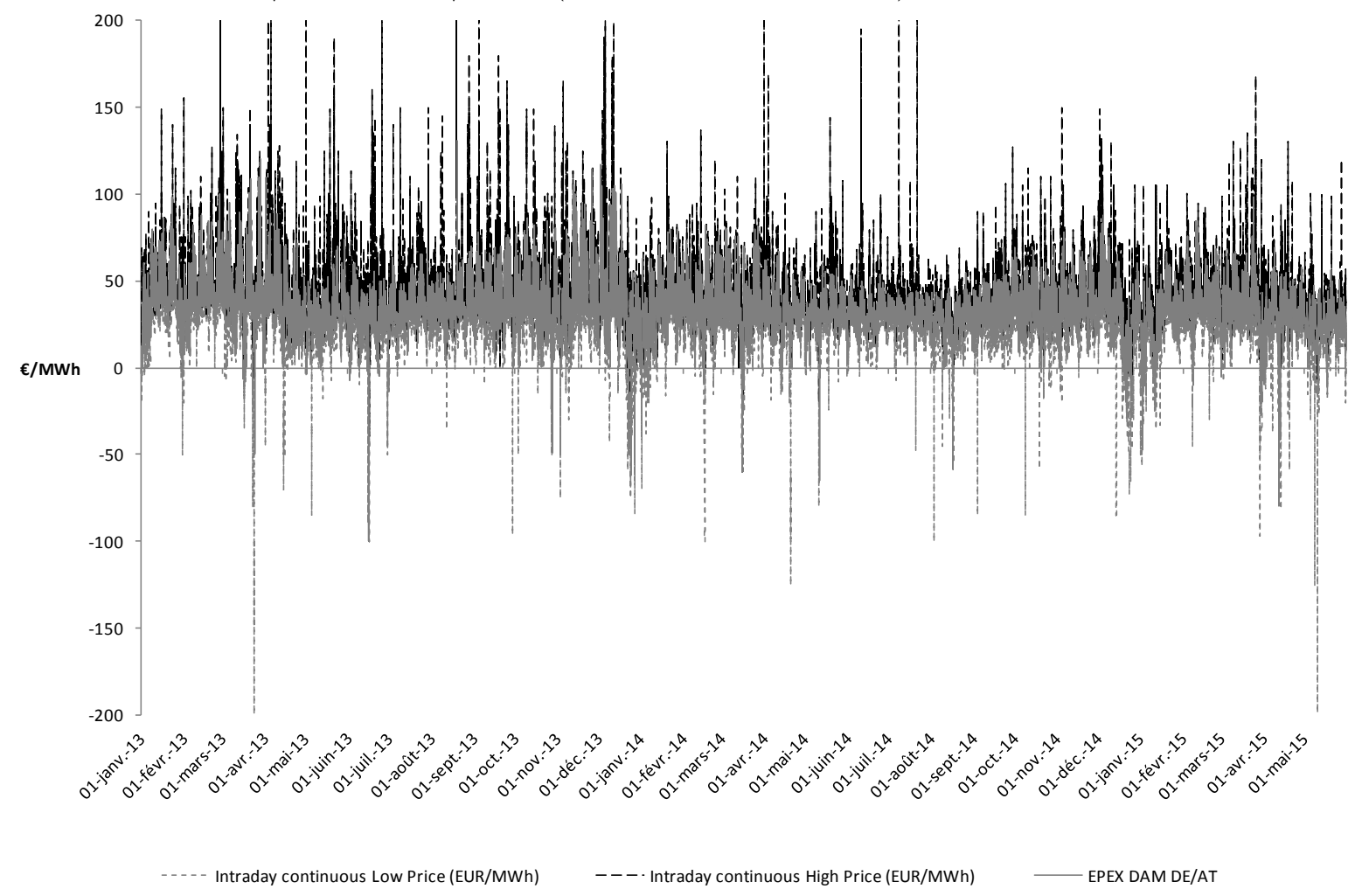




\section{What is flexibility and why do we need it?}

The power system needs flexibility in order to cope with the uncertainty associated with large-scale intermittent resource penetration.

1. At the system level, flexibility is the ability of the system to accommodate increasing levels of uncertainty while maintaining satisfactory levels of performance. System flexibility can be achieved if there are enough flexible resources in the system.

2. At the resource level, flexibility is the ability of to start-up quickly and adjust load output to changing market conditions.

There are several types of resources that can provide flexibility to the system. Some of them can provide more energy (upwards generation/incremental), Hydro and thermal generation plants, some can offer less energy such as wind turbines or demand side resources and some can offer both such as storage resources. Today demand-response capacity is still very limited in Europe and storage costs are still prohibitive for a large scale deployment. Garnier, E. and Madlener [7] explore the benefits that wind and photovoltaic power plant operators can extract from the activation of flexible loads during their market operation on both day-ahead and intraday stages. We focus primarily on the profitability of existing gas power plants. The two most common flexibility parameters are:

1. Start-up/shut-down time: the time required for starting a plant to grid synchronization and actual contribution varies strongly from one technology to the other but in general it has significantly decreased over time. Historically for instance, 
large boilers required from several hours to couple of days to reach full output. This is suitable for baseload operation but under more volatile and uncertain conditions, new plants may be required to turn down and restart more frequently. If CTs and CCGTs have traditionally been faster to start than steam coal plants, several improvements are noticeable for all technologies. Most recent CCGTs have cut starting times by two and can reach full output in hot conditions in around 30 minutes. Older steam plants would require around 800 (or 14 hours) minutes after an outage to reach full power, whilst most recent one can reach full output in 4 hours after the same stop time. Some hydro plants can ramp-up and down in a matter of seconds. This is also true for some storage and Demand Side Management (DSM). (FTN): the modification of consumer demand for energy through various methods such as financial incentives.

2. Minimum-up \& down time: If a thermal production is started up, for a number of technical reasons related to the operation of the thermal plant it should be on for a minimum number of hours known as the minimum up-time. If the unit is shut down it should remain down for a certain number of hours, known as the minimum down-time.

The addition of significant iRES generation is adding pressure on the profitability of conventional power plants by displacing generation with higher variable costs at the far right of the merit order curve. With the current fuel and carbon dioxide (CO2) prices, the power plants that are most displaced in Europe are gas turbines. Several have announced early retirement or mothballing. As a result a number of gas plant operators are facing an unsustainable situation with plants running at a loss or at best hardly recouping fixed 
cost.

The iRES generation that comes online ${ }^{10}$ puts pressure on conventional power plant profitability by displacing generation with higher variable costs at the far right of the merit order curve or by contributing to the appearance of negative prices. With the current fuel and carbon dioxide prices, Europes most displaced power plants are gas turbines (Combined Cycle Gas Turbines (CCGT) or Combustion Turbines (CT). The plant revenues are below the fixed O\&M level several have announced early retirement or mothballing. As a result a number of gas plant operators face an unsustainable situation with plants running at a loss or at best hardly recouping fixed costs. Although average prices have been falling it would be interesting to understand how volatility in short term prices could create the economic conditions to maintain enough flexible capacity to balance the power system.

\section{An example of the need for flexibility}

We present an example of a situation that required flexibility: the solar eclipse in Germany ${ }^{11}$. Solar generation for Friday March 20, 2015 was forecasted at 15 GW before the eclipse, falling below $7 \mathrm{GW}$ at 10:30am and rising sharply above 22 GW around noon. Figures 5 illustrates the volumes and prices for delivery Friday March 20, 2015 against a normal business day in March 2015. Normal business days see important generation ramps within the day but the needs during March 2015 solar eclipse were unprecedented.

\footnotetext{
${ }^{10}$ Most renewable generation resources in Europe have been financed through Feed-in-tariffs. The amount of installed renewable capacity is independent of power prices and operators do not require price-spikes to recover their fixed costs.

${ }^{11}$ This example is derived from Epexspot ??
} 
The Day-Ahead auction and the 15 Minutes auction are based on forecasts of the next day while the continuous markets allows market participants to balance their portfolios until 30mn to real time. As illustrated in Figures 3 and 4, power for delivery Hour 11 jumped in the Day-Ahead auctions to EUR/MWh 49.41 in Germany. On the 15mn auction, during 11:00-11:15 am a price of EUR/MWh 464.37 was observed and between 11:45-12:00 EUR/MWh -164.48. On the 15 minutes continuous intraday, there were also important price swings on the first and fourth contracts of Hour 11. The 11:00-11:15 transactions occurred at prices ranging from 35 to EUR/MWh 382.1, averaging at EUR/MWh 146.5. Most of the transactions of the 11:45-12:00 contract occurred at negative prices, with an average of EUR/MWh -2.7.

Figure 3: Solar Forecast

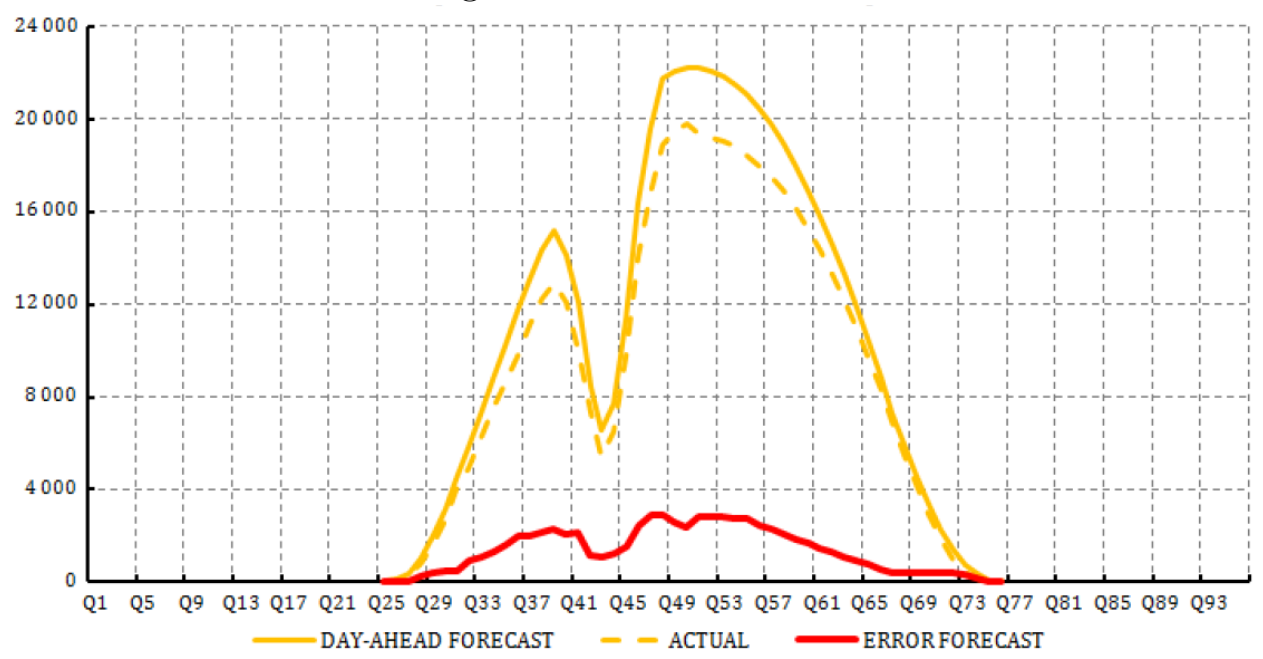


Figure 4: Day-Ahead Prices

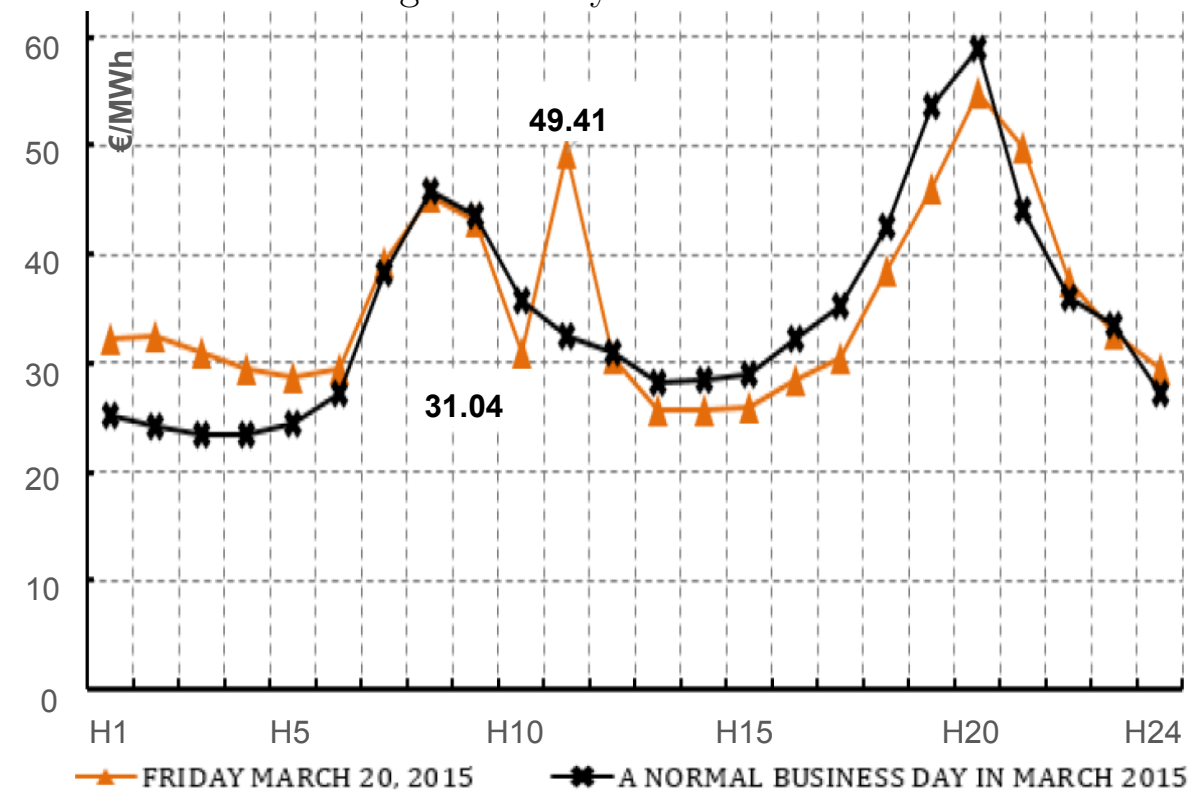

Figure 5: Intraday Prices

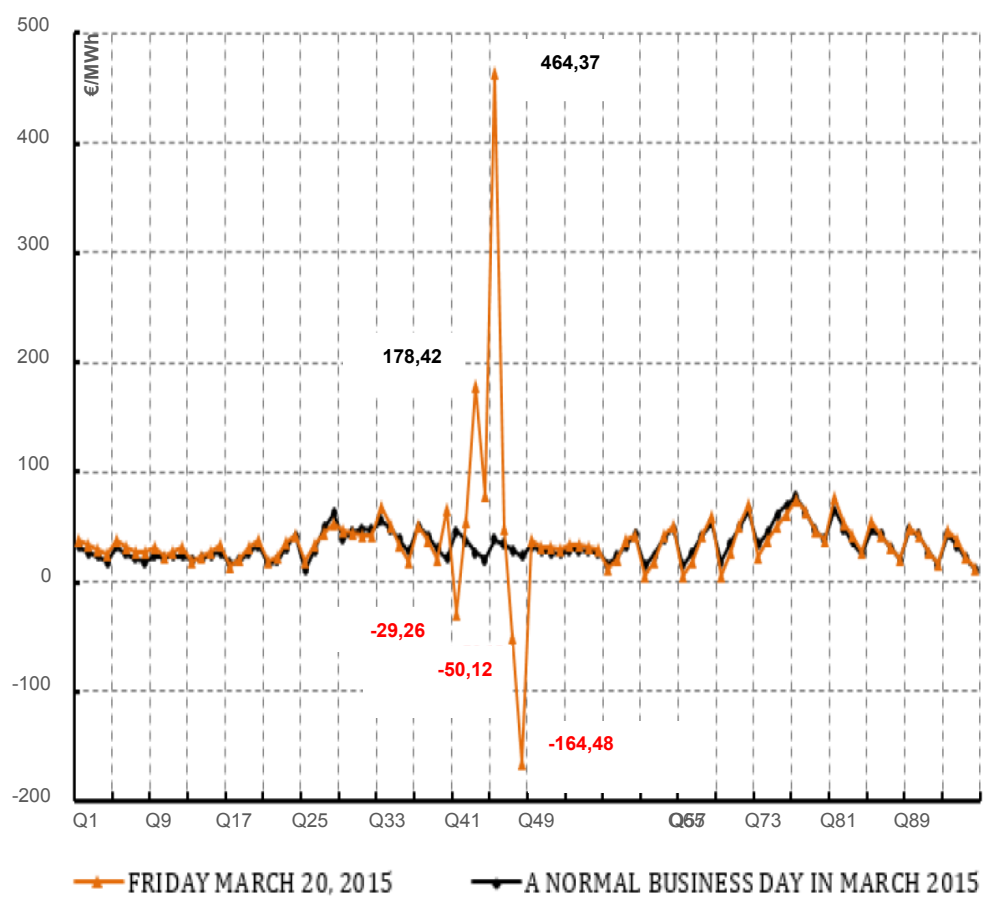


This extreme example illustrates well the interaction between the market and the supply demand balance on the grid with growing flexibility needs induced by the integration of large amounts of intermittent renewable energy

\section{The value of flexibility}

To estimate what revenues a plant could achieve, we have calculated the revenues for a combined-cycle gas turbine (CCGT) offered only on the DAM (case 1) or on the IDM. In order to empirically assess the revenues that a flexible resource can receive, we have computed the net revenues for a perfect MW from a Combined Cycle Gas Turbine (CCGT) able to ramp up and down based on day-ahead or intraday prices. If the price is above the variable cost of the CCGT the plant receives the difference between the market clearing price and its variable costs. If the price is below the variable costs the unit does not produce and has a profit of zero. This is a very simplified unit-commitment as we do not take into account the technical constraints of the power plant (min-up/down time, ramps, efficiency variations,...) nor the impact of the resource on the market clearing price. We have not considered the flexibility value of a demand-response resource or storage but this value can be computed in a similar way using technical parameters, cost estimates and

wholesale power prices (price differentials in the case of storage). The same calculation is done for all markets, continuous or auction, hourly or quarterly.

- If the $A_{t}>V C_{t}$, the margin contribution is equal to $A_{t}-V C_{t}$.

- If the $A_{t}<V C_{t}$, the margin contribution is equal to 0 . 
The following Figure 6 shows results when this calculation is done based on the DAM clearing prices and with the hourly intraday prices ${ }^{12}$. In the first case the CCGT is offered on the DAM only and in the second case the CCGT is offered on the IDM only.

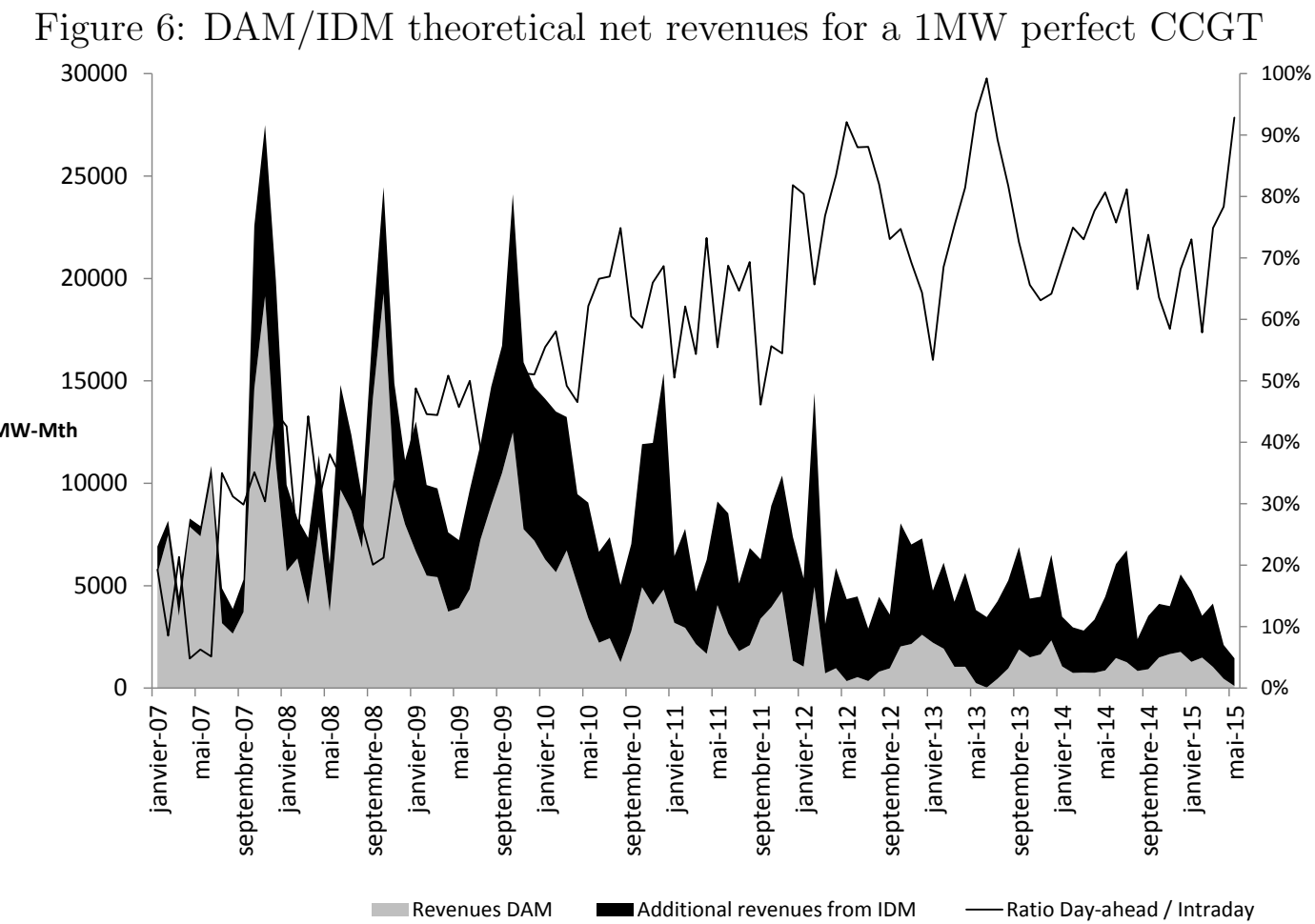

\footnotetext{
${ }^{12}$ For the day-ahead auction we use the market clearing price (hourly or $15 \mathrm{mn}$ ). As the intraday market is a continuous market we have used different proxies as the reference price. We use the Weighted Average Price (WAP), the High (highest price of the trading session) and the Low (lowest price of the trading session). For example, when we use the High make the assumption that the plant manages to get the highest hourly price during the trading session. High/Low overestimates/underestimate the actual revenues that could be earned by a CCGT on the intraday, but allow to determine benchmarks.
} 
Although revenues are low in both markets due to the depressed power prices, the share of revenues from hourly Intraday compared to day-ahead has increased significantly ${ }^{13}$ over recent years. In 2007, a flexible MW could earn 10\% more net revenues by offering its MW to the Intraday market instead of a scheduling in the day-ahead. In 2015, a flexible MW can earn 70-80\% more revenues by offering its MW on the intraday hourly market instead of the day-ahead hourly market.

Table 1: Theoretical net revenues for a perfect CCGT MW dispatched at the spot price.

\begin{tabular}{lccc}
\hline$€ /$ MW-yr & 2013 & 2014 & $2015^{*}$ \\
\hline Day-ahead hourly auction & 15282,19 & 13590,19 & 4367,46 \\
Intraday Continuous hourly price (High) & 59729,39 & 49436,61 & 17833,67 \\
Intraday Continuous hourly price (WAP) & 19629,12 & 16812,89 & 4732,02 \\
Intraday Continuous hourly price (Low) & 4488,55 & 3921,81 & 1246,99 \\
Intraday 15mn Call-Auction & - & - & 26445,23 \\
Intraday Continuous 15mn (High) & 95501,44 & 98187,12 & 33682,18 \\
Intraday Continuous 15mn (WAP) & 33407,95 & 30737,11 & 8162,30 \\
Intraday Continuous 15mn (Low) & 6191,27 & 5203,61 & 1212,21 \\
Intraday 15mn (Min up-time 2hrs) & 89553,26 & 94328,33 & 32517,37 \\
Intraday 15mn (Min up-time 3hrs) & 70757,88 & 77506,94 & 29318,18 \\
Intraday 15mn (Min up-time 8hrs) & 54242,89 & 64046,44 & 24295,34 \\
\hline
\end{tabular}

( ${ }^{*}$ until June 2015).

What happens if instead of hourly prices, the resource is scheduled based on $15 \mathrm{mn}$ prices? A first interesting observation is that between 2013 and 2014 although the quarterly revenues have kept increasing hourly revenues have decreased. On/Off decisions of the plant at the quarterly level can be far more profitable as flexible resources benefit from a much higher price volatility at quarterly level. Although a perfect MW at the

\footnotetext{
${ }^{13}$ There are several factors contributing to this decrease such as low coal/gas and CO2 prices, depressed demand and the renewable capacity additions with low variable costs.
} 
quarterly level is challenging to find in practice, it is interesting to see that it could increase revenues significantly on this quarterly price granularity. As shown in the table below which summarizes results over a year, a perfect MW could increase its revenues by more than $60 \%$ compared to the hourly market from $59 \mathrm{k} / \mathrm{MW}-\mathrm{Yr}$ to $95 \mathrm{k} / \mathrm{MW}$-Yr.

In the auctions that take place on the day-ahead of delivery, the time lag is longer between gate closure and actual delivery and therefore the informational efficiency in these markets tends to be lower (Bellenbaum et al. 2014 [1]). However, it is interesting to look at the results of the same analysis with the $15 \mathrm{mn}$ auction that takes place everyday in Germany at 3pm (3hours after the day-ahead hourly auction) on the day-ahead for the 96 quarters of tomorrow's delivery. Instead of taking the price of the continuous $15 \mathrm{mn}$ market we take the results of the $15 \mathrm{mn}$ Intraday Call-auction. In Table 1, we can see that from the start of 2015 the net revenues received by the perfect CCGT MW on the $15 \mathrm{mn}$ call-auction are 26,5 kEUR/MW-yr, always above the hourly revenues and between the high and WAP prices of the $15 \mathrm{mn}$ continuous market. The difference with the net revenues that can be earned on the $15 \mathrm{mn}$ continuous market remains very significant (almost 30\%). The most rewarding market for a flexible resource remains getting the high prices on the the $15 \mathrm{mn}$ continuous market (33kEUR/MW-yr in 2015), followed by the $15 \mathrm{mn}$ call auction, the hourly continuous market and last but not least the Day-ahead hourly auction.

If we take into account technical constraints that would limit the flexibility of our perfect MW we see that the flexibility revenues decrease back to the level of the hourly market. If for example our perfect MW has minimum up-time constraints and needs to generate over consecutive several quarters before ramping-down, the revenues decrease 
towards the level of hourly Intraday revenues.

The net revenues of the plant under different minimum up-time assumptions (2 hours, 3 hours and 8 hours). The outcome of these estimations is quite intuitive. An inflexible resource would lose the benefits in trading quarterly contracts. 
These empirical estimations reveal two different components for what can be seen as "flexibility". The value of immediacy that can be estimated when comparing the net revenues that can be captured by a flexible resource on the continuous hourly market compared to the hourly day-ahead auction. In 2015 , this value is $8,162-4,367=3,795 \mathrm{EUR} / \mathrm{MW}$ yr for the WAP and 33,682-4,367=29,315EUR/MW-yr for the High prices.

The net revenues obtained on the $15 \mathrm{mn}$ auction are lower than the revenues a market participant could get by offering a flexible resource on the continuous Intraday market and starting it closer to real-time but they are still eight times higher than the hourly auction $(26,445-4,367=22,078 \mathrm{EUR} / \mathrm{MW}-\mathrm{yr})$. This difference can be labelled "flexibility revenue" per se. This difference is also independent from the "immediacy" risk or forecast error risk that can be found on the continuous market. Even if the forecast was perfect, there might still be a need to ramp-up/down large capacity of back-up generation at $15 \mathrm{mn}$ steps. This is the value given, already at the day-ahead stage, by the ability to react to $15 \mathrm{mn}$ price variations and can be priced in an auction. In the next section we investigate the statistical properties and model this "flexibility" value.

These "backward-looking" empirical results allow us to quantify two values for flexibility: (1) The "immediacy" value as we are approaching real-time as the urgency of the delivery increases. This value is revealed during the intraday process and is highly linked to risk (2) the "flexibility" as a resource can capture variations of shorter granularity is more related to asset optimization and can be priced already from the day-ahead. 


\section{Modelling Intraday price volatility and flexibility revenues}

\subsection{The stochastic model}

In the next section we model the prices of electricity and try to quantify "flexibility".

\subsubsection{Auction electricity model and Variable Cost}

Let set a probability space $(\Omega, \mathcal{G}, \mathbb{P})$ where $W^{1,2}=\left(W_{t}^{1,2}\right)_{t \in[0, T]}$ are two Brownian motion over a finite horizon $T<\infty$. Mean-reverting jump diffusion (MRJD) processes have provided the basic building block for electricity spot price dynamics since the very first modeling attempts in the 1990s. Their popularity comes from the fact that they address the basic characteristics of electricity prices (mean reversion and spikes), and at the same time are tractable enough to allow for computing analytical pricing formulas for electricity derivatives. Mean-reverting jump diffusion (MRJD) models have also been used for forecasting hourly electricity spot prices and volatility . A mean-reverting jump diffusion model is defined by a continuous-time stochastic differential equation that governs the dynamics of the spot price process:

$$
d A_{t}=\left(\alpha-\beta A_{t}\right) d t+\sigma d W_{t}^{1}+J d q_{t}, \quad 0 \leq t \leq T .
$$

The Brownian motion $W^{1}$ is responsible for small (proportional to $\sigma$ ) fluctuations around the long-term mean $\frac{\alpha}{\beta}$. Thus $W^{1}$ represents the stochastic evolution of the future 
financial asset such as volatility, jumps ... While an independent compound Poisson (jump) process $q_{t}$ produces infrequent (with intensity $\lambda$ ) but large jumps of size $J$ (here Gaussian with mean $\mu$ and variance $\gamma^{2}$ ). In this study it is reasonable to allow the intercept $\alpha$ to be a deterministic function of time to account for the seasonality prevailing in electricity spot prices.

Concerning the variable cost stochastic process $V C$, it appears that there is no jump component in its dynamic. Thus, this process evolves according to the following stochastic differential equation:

$$
d V C_{t}=V C_{t}\left(\mu d t+\delta d W_{t}^{2}\right), \quad 0 \leq t \leq T
$$

\subsection{Modelling prices before and after the default event}

We are given a nonnegative and finite random variable $\tau$, representing the default time, on $(\Omega, \mathcal{G}, \mathbb{P})$. Consider our two risky assets subject to possible default risk $A_{t}$ and $C V_{t}$. If a default occurs before the maturity $T$ then the volatility and/or jumps intensity components of the stochastic dynamics of the processes $A_{t}$ and/or $C V_{t}$ could be impacted. We can imagine that the volatility of the auction's price could increase of $20 \%$ dues to a crash of a nuclear central in our production.

Remark 5.1. The default time $\tau$ models default events which can occur during the time to maturity. This default time depends on several ecological, environnemental and financial factors.

In our setting of possible default event, we have that the price processes $A_{t}$ and $C V_{t}$ 
are given by :

$$
\begin{aligned}
A_{t} & =A_{t}^{1} 1_{t<\tau}+A_{t}^{2}(\tau) 1_{t \geq \tau}, \quad 0 \leq t \leq T, \\
V C_{t} & =V C_{t}^{1} 1_{t<\tau}+V C_{t}^{2}(\tau) 1_{t \geq \tau}, \quad 0 \leq t \leq T .
\end{aligned}
$$

where $A^{1}$ and $V C^{1}$ represent the dynamics of assets before the possible default event at time $\tau \in[0, T]$. These processes evolve, for all $0 \leq t \leq T$, according to following stochastic differential equations:

$$
\begin{aligned}
d A_{t}^{1} & =\left(\alpha^{1}-\beta^{1} A_{t}^{1}\right) d t+\sigma^{1} d W_{t}^{1}+J^{1} d q_{t}^{1}, \quad A_{0}^{1}=A_{0-} \\
d V C_{t}^{1} & =V C_{t}^{1}\left(\mu^{1} d t+\delta^{1} d W_{t}^{2}\right), \quad V C_{0}^{1}=V C_{0-} .
\end{aligned}
$$

where $q^{1}$ is an independent compound Poisson process with intensity of jumps $\lambda^{1}$ and large jumps of size $J^{1}$ (here Gaussian with mean $\mu^{1}$ and variance $\left.\left(\gamma^{1}\right)^{2}\right)$.

Then $\left\{A_{t}^{2}(\tau), \theta \leq t \leq T, \tau \in[0, T]\right\}$ and $\left\{V C_{t}^{2}(\tau), \theta \leq t \leq T, \tau \in[0, T]\right\}$ are families of processes representing the dynamics of the assets after the default event occur at time $\tau \in[0, T]$ and governed for all $\tau<t \leq T$ by

$$
\begin{aligned}
d A_{t}^{2}(\tau) & =\left(\alpha^{2}(\tau)-\beta^{2}(\tau) A_{t}^{2}(\tau)\right) d t+\sigma^{2}(\tau) d W_{t}^{1}+J^{2}(\tau) d q_{t}^{2} \\
A_{\theta}^{2}(\tau) & =A_{\tau-}^{2}\left(1+\gamma_{\tau}\right) \\
\text { and } & \\
d V C_{t}^{2}(\tau) & =V C_{t}^{2}(\tau)\left(\mu^{2} d t+\delta^{2} d W_{t}^{2}\right) \\
V C_{\theta}^{2}(\tau) & =V C_{\tau-}^{2}\left(1+\gamma_{\tau}\right)
\end{aligned}
$$


Here, we have denotes by $A_{0-}$ and $C V_{0-}$ the initial values of assets and $\gamma$ is a stochastic process valued in $[-1, \infty)$ and representing the jump of the asset $A_{0_{-}}$and $V C_{0-}$ at the default time $\tau$.

Remark 5.2. The special case of a mothballing/retirement of an asset, the auction one A for example, after the default event $\tau$ is modeled with the case $\gamma_{\tau}=-1$ (and $\mu_{t}^{2}(\tau)=$ $\left.\sigma_{t}^{2}(\tau) \equiv 0\right)$. Indeed, this means what when the possible default time occurs the after default price $A_{t}^{2}$ will be equal at the time $\tau$ to

$$
A_{\theta}^{2}(\tau)=A_{\tau-}^{2}\left(1+\gamma_{\tau}\right)=A_{\theta-}^{2}(1-1)=0
$$

And so for all $\tau<t \leq T$

$$
A_{t}^{2}(\tau) \equiv 0
$$

The interpretation of the default risk model for an asset price is the following. The process $A^{1}$ ( or $V C^{1}$ ) represents the asset price before the default, and there is a jump on the asset price at the default time, represented by the process $\gamma$, which may take positive or negative values, corresponding to proportional loss or gain on the asset price. After the default at time $\tau, A^{2}(\tau)\left(\right.$ or $\left.V C^{2}(\tau)\right)$ represents the asset price process, where there is a change of regimes in the coefficients depending on the default time. One typical situation can be as follows: in case of downward (resp. upward) jump in the asset price at default time $\tau \in[0, T]$, the rate of return $\mu^{2}(\tau)$ should be smaller (resp. greater) than the rate of return $\mu^{1}$ before the default, and this gap should increase when the default occurs early, i.e. $\mu^{2}(\tau)$ is increasing (resp. decreasing) in $\tau$ with $\mu^{2}(\tau)<($ resp. $>) \mu^{1}$.

Remark 5.3. In our setting, there are several sources of randomness of both asset prices. 
Indeed, there are the financial market risk modeled with the Brownian motion $W^{1}$ and $W^{2}$; the Poisson jump component $J q_{t}$ of the Auction price process; there are the possible exogenous default event modeled with the stopping time $\tau$, there are the stochastic jump at the default time $\tau$ modeled by $\gamma_{t}$ au and finally the regime switching shift of the parameters before and after the possible default event modeled by the shifting parameters.

\subsection{Default event}

In our framework, we assume that the default event $\tau$ is due to exogenous factors of the stochastic dynamics of the assets price $A$ and $V C$. This means that the random variable $\tau$ is independent to the Brownian motion $W^{1}, W^{2}$ and the Poisson process $q$. Thus we get that there exists a deterministic function $f(\tau)$ of $\tau \in \mathbb{R}^{+}$such that the survival probability is given by

$$
G(t)=\mathbb{P}\left[\tau>t \mid \mathcal{G}_{t}\right]=\mathbb{P}[\tau>t]=\int_{t}^{\infty} f(\theta) d \theta
$$

We assume, in the sequel, that the survival probability follows an exponential distribution with constant default intensity $\lambda$. So there is a constant $\lambda>0$ such that $G(t)=e^{-\lambda t}$ and thus the density function is $f(\theta)=\lambda e^{-\lambda \theta}$. This probability implies that higher is the value of the default intensity $\lambda$, higher is the possibility of a default event in the dynamics of $A$ and $V C$. 


\subsection{Payoff indicators}

We decide to evaluate four financial indicators of our payoff at time $t \in[0, T]$,

$$
\max \left(0, S_{t}-V C_{t}\right)
$$

- At maturity: We calculate the classical payoffs value at maturity

$$
\max \left(0, S_{T}-V C_{T}\right)
$$

- Mean: We calculate the mean payoffs value between time $t=1$ and maturity $t=T$. It corresponds to an average of profits.

$$
\frac{1}{T} \sum_{t=1}^{t=T} \max \left(0, S_{t}-V C_{t}\right)
$$

- VaR: We evaluate the Value at Risk (VaR) of the maturity payoff. The VaR is an aggregated measure of the total risk of a portfolio of contracts and assets. The VaR summarizes the expected maximum loss (worst loss) of a payoff contract over a target horizon (the maturity $T$ ) within a given confidence interval (generally 95\%). Thus, VaR is measured in monetary units, Euros in our article. Maximizing the $\mathrm{VaR}$ is equivalent to increase our profit.

- CVaR: The Conditional Value-at-Risk (CVaR), is strongly linked to the previous risk measure (i.e. VaR) which is, as mentioned above, the most widely used risk measure in the practice of risk management. By definition, the $\operatorname{VaR}$ at level $\alpha \in(0,1)$, 
$\operatorname{VaR}(\alpha)$ of a given portfolio loss distribution is the lowest amount not exceeded by the loss with probability $\alpha$ (usually $\alpha \in[0.95,1)$ ). The Conditional Value at Risk at level $\alpha C \operatorname{VaR}(\alpha)$ is the conditional expectation of the portfolio losses beyond the $\operatorname{VaR}(\alpha)$ level. Compared to $\mathrm{VaR}$, the $\mathrm{CVaR}$ is known to have better mathematical properties. It takes into account the possible heavy tails of portfolio loss distribution. Risk measures of this type were introduced by Artzner et al. (1999) and have been shown to share basic coherence properties (which is not the case of $\operatorname{VaR}(\alpha)$ ).

\section{The Data and Numerical results}

We use the Day-ahead and Intraday historical prices for Germany and France from 2012 to 2015 [4] For day-ahead we use 24 hourly prices per day. For the Intraday we use 96 quarterly prices from the 15mn Call-Auction. The auctions allow a concentration of liquidity at a given point in time. The day-ahead auction which takes place at noon every day and the $15 \mathrm{mn}$ call auction which takes place at $3 \mathrm{pm}$ allow a robust reference price to emerge for all hours/quarters of the next day. In the German auction on average 700GWh and on the quarterly auction 15-20GWh are traded every day. Variable costs for a CCGT are calculated daily based on natural gas and $\mathrm{CO} 2$ prices. They are based on the sum of fuel, emission and Variable O\&M costs for a 1MW CCGT. The payoff is the difference between the price and variable costs when price is above variable costs.

\footnotetext{
${ }^{14}$ EPEX SPOT Day-ahead auction and EPEX SPOT Intraday Continuous.
} 


\subsection{Parameters' estimation and Descriptive statistics}

\subsubsection{Descriptive statistics}

Table 2: Descriptive Statistics of the data.

\begin{tabular}{lcccc}
\hline & \multicolumn{4}{c}{ Markets } \\
& Hourly German & Quarterly German & Hourly France & Variable Costs \\
\hline Mean & 29,8732 & 29,8170 & 32,1707 & 42,9825 \\
Median & 29,5200 & 29,5500 & 33,5137 & 42,8108 \\
Variance & 185,4167 & 274,0573 & 123,7806 & 3,9322 \\
Skewness & $-0,5177$ & 0,7572 & $-0,0485$ & 0,1522 \\
Kurtosis & 6,4304 & 34,2469 & 3,1646 & 2,2572 \\
\hline
\end{tabular}

We estimate the historical volatilities of each market based on returns' prices.

$$
\hat{\sigma}=\sqrt{\frac{1}{N} \sum_{i=1}^{N}\left(R_{i}-\bar{R}\right)^{2}}
$$

where $R_{i}$ denotes the $\mathrm{i}^{\text {th }}$ returns' prices, $R_{i}=A_{i}-A_{i-1}$ (or $R_{i}=V C_{i}-V C_{i-1}$ for Variable Costs), $\bar{R}$ is the empirical mean: $\bar{R}=\frac{1}{N} \sum_{i=1}^{N} R_{i}$ and $N$ denotes the total number of observation.

Table 3: Historical volatilities

\begin{tabular}{ccccc}
\hline & \multicolumn{4}{c}{ Markets } \\
& Hourly German & Quarterly German & Hourly France & Variable Costs \\
\hline$\hat{\sigma}$ & 5.2784 & 14.0843 & 4.1830 & 0.1322 \\
\hline
\end{tabular}

We have a historical profit of 1.1310 euros per MWh for hourly auction german's market and 1.7258 euros per MWh for quarterly auction german's one. In the Figure 6.1.1, we plot the historical data payoff evaluate on the Hourly german's auction prices. 


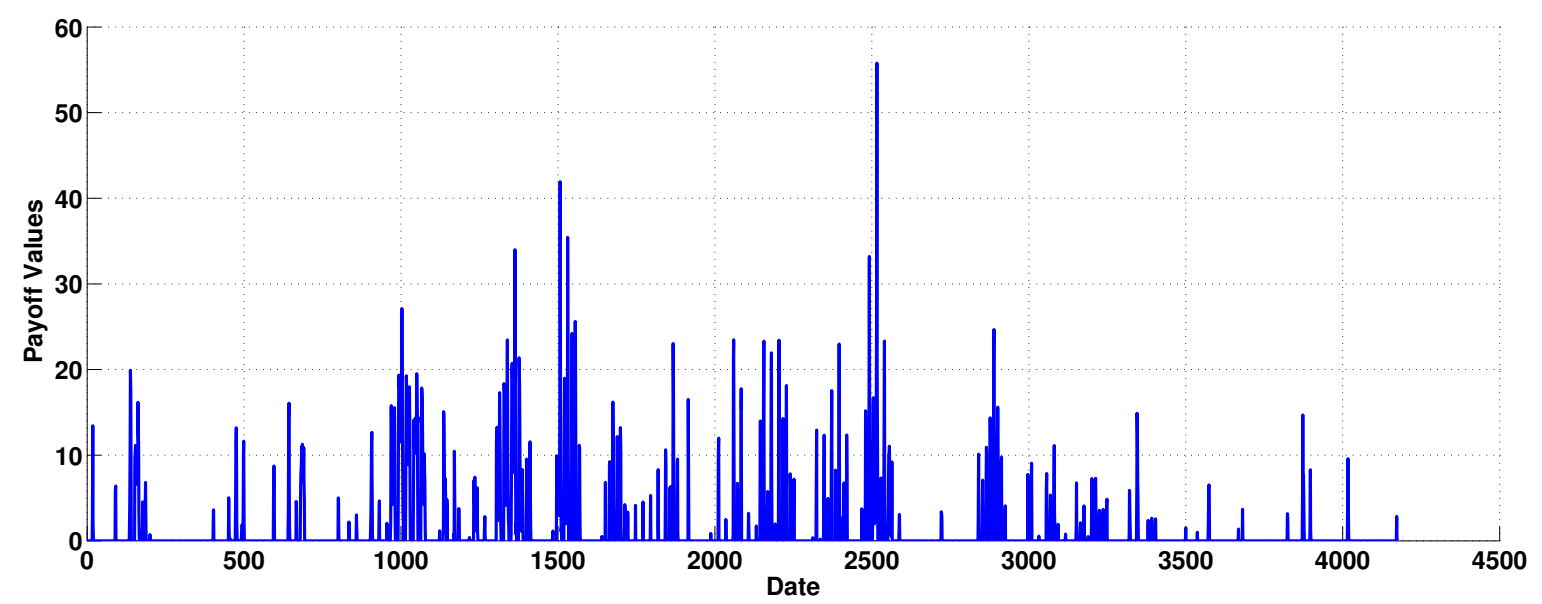

\subsubsection{Parameters' estimation}

We estimate the parameters of the three price series.

Table 4: Parameters' estimation

\begin{tabular}{lcccccc} 
Market & $\alpha$ & $\beta$ & $\sigma$ & $\mu$ & $\gamma$ & $\lambda$ \\
\hline Hourly Germany & 1,2893 & 0,0637 & 13,9939 & 11,5661 & 3,0406 & 0,0394 \\
Quarterly Germany & 11,6492 & 0,3826 & 13,7145 & 367,0112 & 4,8053 & 0,0569 \\
Hourly France & 4,9449 & 0,1198 & 11,7719 & 41,2667 & 1,0000 & 0,0030
\end{tabular}

$\alpha$ and $\beta$ significantly higher for the quarterly auction, same for $\gamma$ and lambda the variance of the jumps and their intensity. The model volatility is higher for the hourly german power prices. 


\subsection{Numerical results}

The Monte Carlo simulation ${ }^{15}$ procedure applied takes random draws from the distributions of both the electricity price and the variable cost of the CCGT. We perform the simulations for both the Day-ahead hourly auction and the $15 \mathrm{mn}$ Call-Auction price distributions for different maturities. The table 5 summarizing the results for the hourly and quarterly prices is shown below

Table 5: Day-ahead hourly auction and the 15mn Call-Auction price distributions for different maturities.

\begin{tabular}{llllllll}
\multicolumn{1}{c}{ Maturities } \\
& & One Month & Two Months & Six Months & One Year & Two Years & Five Years \\
\hline Hourly & $\mathrm{T}$ & 1.3426 & 1.4274 & 2.1530 & 3.6655 & 6.2740 & 13.9554 \\
Germany & Mean & 1.1824 & 1.2802 & 1.6579 & 2.3701 & 3.7330 & 7.7968 \\
& VaR & 1.3227 & 1.4949 & 2.1984 & 3.5536 & 6.2273 & 13.5885 \\
& CVaR & 1.3545 & 1.5264 & 2.2819 & 3.6389 & 6.3527 & 13.9075 \\
\hline Quaterly & T & 2.2247 & 2.5715 & 3.6244 & 5.5253 & 8.8871 & 18.8654 \\
Germany & Mean & 2.1426 & 2.3801 & 2.9515 & 3.8024 & 5.5071 & 14.4534 \\
& VaR & 2.3019 & 2.6773 & 3.7040 & 5.3328 & 8.4945 & 18.4397 \\
& CVaR & 2.3365 & 2.7379 & 3.7842 & 5.4551 & 8.6848 & 18.9235 \\
\hline Hourly & T & 1.4137 & 1.5898 & 2.6080 & 4.4691 & 7.9749 & 17.1619 \\
& Mean & 1.2439 & 1.3822 & 1.8941 & 2.8458 & 4.6306 & 9.6757 \\
& VaR & 1.4088 & 1.6517 & 2.6129 & 4.4092 & 7.8386 & 16.6777 \\
& CVaR & 1.4385 & 1.6928 & 2.7060 & 4.5131 & 7.9829 & 17.0244 \\
\hline
\end{tabular}

For the three series the patterns appear quite similar. Results of the Monte Carlo simulations show that these revenues start low (1.18 (DE Hourly)- 2.14 (DE Quarter) EUR/MWh) but increase rapidly between 2 and 5 year maturities $(7.80-14.45$ EUR/MWh). At 5 year maturities, auction revenues are eight times higher then their current levels.

\footnotetext{
${ }^{15}$ we used 5000 simulations in our results since we tested a range of number of simulations between 1000 to 10000 to confirm this choice regarding the convergence of the results.
} 
When we compare the results for Germany with France, for the one month maturities, the average payoff ranges from 1,24 (FR hourly) to 1,18/MWh (DE hourly) and for the five year maturities from 9,68 to 7,80 / MWh.

It is interesting to see that between two and five years maturity, the payoff more than doubles for the three series, For the quarterly auction, the payoff is almost multiplied by a factor of three. What happens if we increase volatility and jump parameters?

\subsubsection{Impact of volatility and jump at default time}

We model the short-term prices both hours and quarters as mean-reverting jump diffusion (MRJD) processes. The following tables summarize the numerical results for the German hourly and quarterly auctions when the volatility and jump parameters vary. As expected, for all cases the payoff of the flexible MW increases as the volatility and jump parameters increase at default time. However, they do not grow at the same rate. When volatility and jumps increase by $100 \%$ :

- the payoff of the hourly auction increases from 1,2/MWh (standard mean) to 5,1/MWh (mean) and to 6,9/MWh for CVaR.

- the payoff of the quarterly auction increases from 2,14/MWh (standard mean) to 7,6/MWh (mean) and to 9,7/MWh for CVaR

The revenues from the quarterly market are significantly higher than the hourly revenues. Profitability increases as volatility and jump parameters increase.

As can be seen in Table 6, when increasing price volatility and intensity jumps unlike profits in terms of margin differences between $60 \mathrm{mn} / 15 \mathrm{mn}$ auction decrease. This is 
because we end up with two markets that are both very volatile and very spiky. This mitigates their different dynamics. It was indeed a smoothing phenomenon specific properties to these two markets towards a single market.

\subsubsection{Differences between hourly and quarterly revenues}

We then compare the differences between the hourly and quarterly prices (see Table 8). If volatility and jumps increase from 0 to $100 \%$, the difference decreases from 81 to $49 \%$. Thus, increasing the jump process tends to smooth differences between quarterly and hourly auctions (where jumps are currently very modest). It is interesting to note that this difference tends to strongly decrease with jumps but increase with volatility, up to $50 \%$. For example, when we increase volatility by $50 \%$ the difference between hourly and quarterly payoff grows from $81 \%$ to $105 \%$ but an increase of $100 \%$ brings the difference down to $42 \%$.

When we increase the price volatility and the intensity of jumps, the difference in net revenues between $60 \mathrm{mn} / 15 \mathrm{mn}$ auctions increases with increases of volatility of 10 and $50 \%$ and decreases with the intensity of jumps. At first sight, this seems counter-intuitive. One explanation is that we end up with two markets that are both very volatile and very "spiky". The spikes/jumps are very powerful in increasing the net revenues; This mitigates their different dynamics between 15 and $60 \mathrm{mn}$ auction prices. It is indeed a smoothing of the specific properties of each market towards a market with common/similar properties 


\section{Conclusion and policy recommendations}

We have seen that a flexible plant can increase its revenues by ramping up/down close to real-time and/or quarter by quarter. Volatility of short term prices provides an additional revenue to the flexible resources able to react quickly as real-time approaches. We have found that the empirical "backward-looking" net revenues that can be captured by a flexible resource able to react to the short term price variations in the day-ahead and intraday markets. We find that although the profitability has been decreasing on both markets, the difference in profitability between day-ahead and intraday markets has been increasing significantly. This is even more pronounced when we look at $15 \mathrm{mn}$ prices. Already from the day-ahead stage, in the $15 \mathrm{mn}$ auction, this flexibility (the ability to tamp up/down at $15 \mathrm{mn}$ intervals) has a strong value/premium compared the hourly auction.

These "backward-looking" empirical results allow us to quantify two values for flexibility:

1. The "immediacy" value as we are approaching real-time as the urgency of the delivery increases. This value is revealed during the intraday process and is highly linked to risk

2. the "flexibility" as a resource can capture variations of shorter granularity is more related to asset optimization and can be priced already from the day-ahead.

In the second part of this paper, we quantify this "flexibility" component. We model the prices of the two auctions that take place in the day-ahead of delivery (hourly and $15 \mathrm{mn}$ ) as mean-reverting jump diffusion (MRJD) process to understand the dynamics 
of flexibility revenues as volatility and number of jumps increase. Results of the Monte Carlo simulations show that these revenues start low (1.2 - 2.2 EUR/MWh) but increase rapidly between 2 and 5 year maturities (7.8 - 14.4 EUR/MWh). At 5 year maturities, auction revenues are seven times higher then their current levels. The revenues from the quarterly market are significantly higher than the hourly revenues. As expected, profitability increases as volatility and jump parameters increase, however it is interesting to observe that the difference between the hourly and quarterly net revenues tends to increase with volatility (up to a $50 \%$ ) but decreases with jumps.

This analysis highlights the importance of the Intraday market to economically maintain enough flexible resources to back the intermittent generation. More granular products such as $15 / 30 \mathrm{mn}$ (and potentially $5 \mathrm{mn}$ at a later stage) should be generalized to improve the price signal for the operation of the power system but also to guide the investments in the countries that are likely to see a strong growth in intermittent generation capacity over the coming years. We can expect the value of immediacy to decrease with improved forecasting techniques but the need to have enough flexibility to account for the large generation ramps will increase.

\section{References}

[1] Bellenbaum, J., Bucksteeg, M., Kallabis, T., Pape, C., Weber, C., (2014). Intra-Day Cross-Zonal Capacity Pricing. Study on behalf of OFGEM. 
[2] Bunn, D., Andresen, A., Chen, D. and Westgaard, S. (2016) . Analysis and Forecasting of Electricty Price Risks with Quantile Factor Models. Energy Journal, 37 (1).

[3] Ciarreta, A. and Zarraga, A. (2015) . Analysis of mean and volatility price transmissions in the MIBEL and EPEX electricity spot markets. Energy Journal 36(4).

[4] Epexspot (2015). European Power Exchange as a component of security of supply during the solar eclipse.

[5] Kevin F. Forbes, K.F. and Zampelli, E.M. (2014). Do Day-Ahead Electricity Prices Reflect Economic Fundamentals? Evidence from the California ISO. Energy Journal $35(3), 129-144$.

[6] Garnier, E. and Madlener, R., (2015). Balancing forecast errors in continuous-trade intraday markets. Energy Systems, 6 (3), 361-388.

[7] Garnier, E. and Madlener, R., (2015). Day-ahead versus intraday valuation of flexibility for photovoltaic and wind power systems. In Operations Research Proceedings 2014. Selected Papers of the International Annual Conference of the German Operations Research Society (GOR), RWTH Aachen, Germany, September 2-5, 2014 [forthcoming].

[8] Hagemann S. and C. Weber, (2015). Trading volumes in intraday markets theoretical reference model and empirical observation in selected European markets, EWL Working Paper No. 03/15 
[9] Hirth, L. (2015). The Optimal Share of Variable Renewables: How the Variability of Wind and Solar Power affects their Welfare-optimal Deployment. Working Paper: DOI: http://dx.doi.org/10.5547/01956574.36.1.6

[10] Joskow, P. L., (2008). Lessons learned from electricity market liberalisation, Energy Journal. 29, 9-42.

[11] Mauritzen, M. (2015). Now or Later? Trading Wind Power Closer to Real Time And How Poorly Designed Subsidies Lead to Higher Balancing Costs. Energy Journal, 36 $(4)$.

[12] Nicolosi, M. (2010). Wind power integration, negative prices and power system flexibility - an empirical analysis of extreme events in Germany. EWI Working Paper, No. $10 / 01$.

[13] Salah Abou El-Enien, A. (2015). Flexibility is the answer: European power exchange as a component of secutity of supply during the solar eclipse European Power Exchange, Epexspot.

[14] Schweppe, F.C., Caramanis, M.C., Tabors, R.D., Bohn, R.E. (1988). Spot Pricing of Electricity Kluwer Academic Publishers.

[15] Thoenes; S. (2014). Understanding the Determinants of Electricity Prices and the Impact of the German Nuclear Moratorium in 2011. Energy Journal, 35(4).

[16] Vassilopoulos, P, Salah, A (2013), The Intraday Paradigm: An Agile Market to Remunerate Flexibility and Integrate Intermittency, Cambridge Energy Research Associates. 
[17] Weber, C., (2010). Adequate Intraday Market Design to Enable the Integration of Wind Energy into the European Power Systems. Energy Policy, 38(7): 3155-3163. 


\section{Appendix}

Table 6: Hourly payoff for variations of the volatility and jump parameters at default time

\begin{tabular}{llllll} 
& & Jumps & Jumps & Jumps & Jumps \\
& & increase $0 \%$ & increase $10 \%$ & increase $50 \%$ & increase 100\% \\
\hline Standard & T & 1.3426 & 1.5909 & 2.2193 & 2.8774 \\
Increase Vol 0\% & Mean & 1.1824 & 1.3924 & 1.8542 & 2.3397 \\
& VaR & 1.3227 & 1.5906 & 2.2788 & 3.0004 \\
& CVaR & 1.3545 & 1.6179 & 2.3114 & 3.0307 \\
\hline Increase & T & 1.5431 & 1.6958 & 2.5716 & 3.1813 \\
Vol 10\% & Mean & 1.3477 & 1.5533 & 2.2381 & 2.7434 \\
& VaR & 1.5409 & 1.7423 & 2.5675 & 3.2488 \\
& CVaR & 1.5683 & 2.2332 & 2.5967 & 3.2921 \\
\hline Increase & $\mathrm{T}$ & 2.2932 & 3.3453 & 4.2421 & 5.7704 \\
Vol 50\% & Mean & 1.9917 & 2.7897 & 3.7735 & 5.1319 \\
& VaR & 2.3650 & 3.3666 & 4.2718 & 5.7364 \\
\hline Increase & $\mathrm{CVaR}$ & 2.3952 & 3.4117 & 4.3270 & 5.8085 \\
Vol 100\% & $\mathrm{T}$ & 5.0448 & 5.1444 & 5.9250 & 6.5956 \\
& $\mathrm{Mean}$ & 4.1317 & 4.6307 & 4.4664 & 5.0751 \\
& $\mathrm{VaR}$ & 5.0638 & 5.1648 & 5.9516 & 6.8170 \\
\hline Increase & $\mathrm{CVaR}$ & 5.1273 & 5.2351 & 6.0276 & 6.8823 \\
Vol -50\% & $\mathrm{T}$ & 0.4349 & 0.6368 & 1.0943 & 1.6767 \\
& $\mathrm{Mean}$ & 0.4548 & 0.5365 & 1.0610 & 1.4688 \\
& VaR & 1.0925 & 0.6209 & 1.1686 & 1.7689 \\
& $\mathrm{CVaR}$ & 1.1946 & 0.6508 & 1.1846 & 1.7930 \\
\hline
\end{tabular}

*Until 15th of June. 
Table 7: Quarterly payoff for variations of the volatility and jump parameters at default time

\begin{tabular}{llllll} 
& & Jumps & Jumps & Jumps & Jumps \\
& & increase $0 \%$ & increase $10 \%$ & increase 50\% & increase 100\% \\
\hline Standard & T & 2.2247 & 2.0390 & 2.6683 & 3.1884 \\
Increase Vol 0\% & Mean & 2.1426 & 2.0987 & 2.3992 & 3.1221 \\
& VaR & 2.3019 & 2.2830 & 2.8618 & 3.3100 \\
& CVaR & 2.3365 & 2.3399 & 2.9177 & 3.3521 \\
\hline Increase & T & 2.6491 & 2.7522 & 3.6851 & 4.5307 \\
Vol 10\% & Mean & 2.6560 & 2.5423 & 3.5763 & 4.3488 \\
& VaR & 2.8461 & 2.7567 & 3.8049 & 4.5662 \\
& CVaR & 2.8814 & 2.8025 & 3.8515 & 4.6094 \\
\hline Increase & $\mathrm{T}$ & 4.8098 & 4.9516 & 5.6939 & 6.7833 \\
Vol 50\% & Mean & 4.0551 & 4.4262 & 5.1494 & 6.7155 \\
& VaR & 4.9142 & 5.1243 & 6.0987 & 7.0976 \\
& $\mathrm{CVaR}$ & 5.4526 & 5.1907 & 6.4312 & 7.1572 \\
\hline Increase & $\mathrm{T}$ & 6.8524 & 7.8182 & 8.3897 & 9.2768 \\
Vol 100\% & Mean & 5.8975 & 5.6877 & 6.3145 & 7.5690 \\
& VaR & 7.3780 & 8.1734 & 8.6544 & 9.5712 \\
& $\mathrm{CVaR}$ & 7.4799 & 8.2612 & 8.7519 & 9.6534 \\
\hline Increase & $\mathrm{T}$ & 0.7438 & 0.8445 & 1.3487 & 2.4310 \\
Vol -50\% & Mean & 0.9623 & 0.8527 & 1.8126 & 1.9096 \\
& VaR & 2.2062 & 0.9317 & 2.0208 & 2.3866 \\
& $\mathrm{CVaR}$ & 2.2589 & 0.9672 & 2.0626 & 2.8343 \\
\hline
\end{tabular}


Table 8: Differences of profits between hourly and quarterly revenues for variations of the volatility and jump parameters at default time

\begin{tabular}{llllll} 
& & Jumps & Jumps & Jumps & Jumps \\
& & increase $0 \%$ & increase $10 \%$ & increase 50\% & increase 100\% \\
\hline Standard & T & 0.6570 & 0.2817 & 0.2023 & 0.1081 \\
Increase Vol 0\% & Mean & 0.8120 & 0.5073 & 0.2939 & 0.3344 \\
& VaR & 0.7403 & 0.4354 & 0.2558 & 0.1032 \\
& CVaR & 0.7250 & 0.4462 & 0.2623 & 0.1060 \\
\hline Increase & T & 0.7168 & 0.6230 & 0.4330 & 0.4242 \\
Vol 10\% & Mean & 0.9707 & 0.6368 & 0.5979 & 0.5852 \\
& VaR & 0.8470 & 0.5822 & 0.4819 & 0.4055 \\
& CVaR & 0.8373 & 0.2549 & 0.4832 & 0.4001 \\
\hline Increase & T & 1.0975 & 0.4802 & 0.3422 & 0.1755 \\
& Mean & 1.0360 & 0.5866 & 0.3646 & 0.3086 \\
Increase & VaR & 1.0779 & 0.5221 & 0.4277 & 0.2373 \\
Vol 100\% & CVaR & 1.2764 & 0.5214 & 0.4863 & 0.2322 \\
& T & 0.3583 & 0.5197 & 0.4160 & 0.4065 \\
& Mean & 0.4274 & 0.2283 & 0.4138 & 0.4914 \\
\hline Increase & VaR & 0.4570 & 0.5825 & 0.4541 & 0.4040 \\
Vol -50\% & CVaR & 0.4589 & 0.5780 & 0.4520 & 0.4026 \\
& T & 0.7102 & 0.3261 & 0.2326 & 0.4498 \\
& Mean & 1.1158 & 0.5894 & 0.7084 & 0.3001 \\
& VaR & 1.0194 & 0.5007 & 0.7293 & 0.3493 \\
& CVaR & 0.8910 & 0.4861 & 0.7412 & 0.5808 \\
\hline
\end{tabular}


Figure 7: Recap of empirical simulation results for the simplified unit commitment of a 1MW perfect resource (source: Source: Own calculations, EPEX SPOT, ICE).

\begin{tabular}{|c|c|c|c|}
\hline$€ / M W-y r$ & 2013 & 2014 & 2015* \\
\hline $\begin{array}{l}\text { Intraday hourly } \\
\text { (High) }\end{array}$ & 59729,39 & 49436,61 & 17833,67 \\
\hline $\begin{array}{l}\text { Intraday hourly price } \\
\text { (WAP) }\end{array}$ & 19629,12 & 16812,89 & 4732,02 \\
\hline $\begin{array}{l}\text { Intraday hourly price } \\
\text { (Low) }\end{array}$ & 4488,55 & 3921,81 & 1246,99 \\
\hline $\begin{array}{l}\text { Intraday quarterly } \\
\text { (High) }\end{array}$ & 95501,44 & 98187,12 & 33682,18 \\
\hline $\begin{array}{l}\text { Intraday quarterly } \\
\text { (Min up time } 2 \mathrm{hrs} \text { ) }\end{array}$ & 89553,26 & 94328,33 & 32517,37 \\
\hline $\begin{array}{l}\text { Intraday quarterly } \\
\text { (Min up time 3hrs) }\end{array}$ & 70757,88 & 77506,94 & 29318,18 \\
\hline $\begin{array}{l}\text { Intraday quarterly } \\
\text { (Min up time 8hrs) }\end{array}$ & 54242,89 & 64046,44 & \multirow[b]{2}{*}{8162,30} \\
\hline $\begin{array}{l}\text { Intraday quarterly } \\
\text { (WAP) }\end{array}$ & 33407,95 & 30737,11 & \\
\hline $\begin{array}{l}\text { Intraday quarterly } \\
\text { (Low) }\end{array}$ & 6191,27 & 5203,61 & 1212,21 \\
\hline Day-ahead market & 15282,19 & 13590,19 & 4367,46 \\
\hline
\end{tabular}

